\title{
A systematic methodology to extend the applicability of a bioconversion model for the simulation of various co-digestion scenarios
}

Kovalovszki, Adam; Alvarado-Morales, Merlin; Fotidis, loannis; Angelidaki, Irini

Published in:

Bioresource Technology

Link to article, DOI:

10.1016/j.biortech.2017.03.101

Publication date:

2017

Document Version

Peer reviewed version

Link back to DTU Orbit

Citation (APA):

Kovalovszki, A., Alvarado-Morales, M., Fotidis, I., \& Angelidaki, I. (2017). A systematic methodology to extend the applicability of a bioconversion model for the simulation of various co-digestion scenarios. Bioresource Technology, 235, 157-166. https://doi.org/10.1016/j.biortech.2017.03.101

\section{General rights}

Copyright and moral rights for the publications made accessible in the public portal are retained by the authors and/or other copyright owners and it is a condition of accessing publications that users recognise and abide by the legal requirements associated with these rights.

- Users may download and print one copy of any publication from the public portal for the purpose of private study or research.

- You may not further distribute the material or use it for any profit-making activity or commercial gain

- You may freely distribute the URL identifying the publication in the public portal 
1 A systematic methodology to extend the applicability of a

2 bioconversion model for the simulation of various co-digestion

3 scenarios

4

5 Adam Kovalovszki, Merlin Alvarado-Morales, Ioannis A. Fotidis, Irini

6 Angelidaki*

7

8 Department of Environmental Engineering, Technical University of Denmark,

9 Bygningstorvet Bygning 115, DK-2800 Kgs. Lyngby, Denmark

10

$11{ }^{*}$ Corresponding Author: Department of Environmental Engineering, Technical

12 University of Denmark, DK-2800 Kgs. Lyngby, Denmark, Phone: (+45) 45251418;

13 Fax: (+45) 45933850; e-mail: iria@env.dtu.dk

14

15 Running title

16 Model simulating manure- and wastewater- based anaerobic co-digestion.

17 


\section{ABSTRACT}

19 Detailed simulation of anaerobic digestion (AD) requires complex mathematical models and the optimization of numerous model parameters. By performing a systematic methodology and identifying parameters with the highest impact on process variables in a well-established AD model, its applicability was extended to various co-digestion scenarios. More specifically, the application of the step-by-step methodology led to the

24 estimation of a general and reduced set of parameters, for the simulation of scenarios where either manure or wastewater were co-digested with different organic substrates.

26 Validation of the general parameter set involved the simulation of laboratory-scale data

27 from three continuous co-digestion experiments, treating mixtures of different organic

28 residues either at thermophilic or mesophilic conditions. Evaluation of the results

29 showed that simulations using the general parameter set fitted experimental data quite

30 well, indicating that it offers a reliable reference point for future simulations of 31 anaerobic co-digestion scenarios.

\section{KEYWORDS}

33 Anaerobic digestion, mathematical modeling, dynamic simulation, organic residue, 34 parameter set.

\section{$35 \quad 1$ Introduction}

36 Throughout the years, various mathematical models simulating both anaerobic

37 mono- and co-digestion processes have been proposed. From simpler empirical models

38 (Andrews, 1969; Graef and Andrews, 1974; Hill and Barth, 1977; Kleinstreuer and 39 Poweigha, 1982), to more complex ones (Angelidaki et al., 1999, 1993; Batstone et al., 
2002b; Costello et al., 1991; Siegrist et al., 1993). All of these models have been used to describe, to a certain extent, the anaerobic digestion of complex substrates.

The majority of the complex models are specialized in anaerobic digestion of specific feedstocks such as agricultural energy crops, residues, manures and wastewater sludge. For instance, the Anaerobic Digestion Model No. 1 or ADM1 (Batstone et al., 2002b) has been the most prominent among scientists working in the field of anaerobic wastewater treatment processes and more recently in solid waste bioconversion technologies. Likewise, the model (BioModel) proposed by Angelidaki et al. (1999) gives a good description of manure-based anaerobic digestion systems. The BioModel focuses on ammonia inhibition, which is often relevant in manure-based digestions, and includes a detailed description of $\mathrm{pH}$ and temperature, in order to simulate free ammonia concentrations. Compared to the ADM1, which expresses the concentration of solid substrate and product components using the indirect Chemical Oxygen Demand (COD), the BioModel features a more convenient, mass-based unit system. This allows

54 for the characterization of substrates and products using simpler sampling and measurement techniques more appropriate for slurries and solid wastes, than COD. Despite their extensive application, the optimal use of such complex models requires the adjustment or modification of numerous parameters, depending on the type and nature of the simulated case (Donoso-Bravo et al., 2011). General experience shows, however,

59 that the more parameters are contained in a mathematical model, the more difficult it

60 becomes to verify their values for individual cases. Specifically, the large number of

61 reactions and chemical species involved in these models gives a better description of the process, but complicates modeling, and - depending on the system to be "modeled" -

63 the selection of the model itself to use. This also implies that existing complex models 
64 are currently incapable of simulating dynamic processes describing diverse experimental conditions, without a considerable amount of customization. Criteria to select among models must weigh the trade-off between increased information requirements and potentially better process description. Moreover, the model refinement is an iterative procedure where the experimental and expert guided process of adding, excluding, or modifying assumptions until a model that satisfactorily explains the experimental data is obtained, is in general a difficult and time-consuming task (SalesCruz and Gani, 2006).

Based on aforementioned premises, the objective of this study was to identify a set of "benchmark" parameters that can be used without previous calibration for specific digestion cases and which can satisfactorily describe different digestion cases such as manure- or wastewater-based digestions. This was achieved through the application of a systematic methodology, which essentially consisted of the following. First, parameter selection was performed to reduce the parameter space for further treatment, based on a detailed assessment of complex bioconversion model parameters, found to be reported in literature with the greatest variations in their values. Second, detailed parameter 80 sensitivity analysis using Latin Hypercube Sampling (LHS) and the Partial Rank

81 Correlation Coefficient (PRCC) methods was performed, so that the less sensitive parameters could be further discriminated/eliminated. Third, numerical optimization using the Simulated Annealing (SA) method was carried out to estimate optimal parameter values and statistical information was obtained to determine the feasibility of 85 the model parameters. Finally, the resulting set of optimized parameters was validated with three selected experimental case studies, in order to demonstrate improved model efficiency when using optimized parameters for simulation. 


\section{Materials and MethodsModel Description}

The core dynamic model (BioModel) of this work was developed by Angelidaki et al. $(1999,1993)$ and describes the degradation of complex substrates, along with the codigestion of different types of organic wastes. In the BioModel, the substrate is described in terms of its basic organic components’ composition - carbohydrates, lipids and proteins -, the concentration of intermediates such as volatile fatty acids (VFA) and long-chain fatty acids (LCFA), and important inorganic components, such as ammonia, phosphate, cations and anions. The model was upgraded to include the hydrolysis of lipids so that it includes three enzymatic hydrolytic and eight bacterial steps, and involves 19 chemical compounds, together with a detailed description of $\mathrm{pH}$ and temperature characteristics. Free ammonia, VFA and LCFA constitute the primary modulating factors. The BioModel was previously calibrated with experimental codigestion scenarios utilizing substrates rich in carbohydrates, proteins and lipids

101 (Angelidaki et al., 1999, 1997). For a detailed description of the model, see Table SI in the Supplementary material.

\subsection{Computational Methods}

Initially written in Microsoft Pascal, and later translated to the Delphi Pascal programming language, the BioModel was recently implemented in MATLAB, combined with a Microsoft Excel-based data input and output platform. The MATLAB

107 model is able to simulate the AD process in one anaerobic fermenter, considering the

108 composition of the inoculum, a primary substrate and up to three optional co-substrates.

109 Organization and processing of parameters defining substrates, pump and flow rates, 110 metabolic steps and chemical components, as well as the collection of model output

111 variables was set up similar to as described by Angelidaki et al. (1999). Integration of 
112 model equations in time and the selection of a suitable time step for calculations also

113 resembled the method outlined in this earlier publication, and for the solution of the

114 model ordinary differential equation system, MATLAB's ode15s solver was used.

\section{$115 \quad 2.3$ Systematic methodology}

116 The four steps describing the systematic methodology are depicted in Figure 1 and

117 are described further in the following subsections. During the analysis, the model

118 structure was kept as taken from the literature (Angelidaki et al., 1999).

\subsubsection{Step 1: Parameter selection}

In this step, a preliminary selection of the model parameters was performed based on the assessment of available literature (Batstone et al., 2002a; Biernacki et al., 2013; Bułkowska et al., 2015; López and Borzacconi, 2010; Lübken et al., 2007; Nguyen, 2014; Ramirez et al., 2009; Rivera-Salvador et al., 2014; Rosén and Jeppsson, 2006).

Details of this process are explained in the Supplementary material and the complete list of parameters considered is shown in the Supplementary material, Table SII. As a systematic reduction of the complete model parameter space and based on the comparison of studies, biochemical parameters that showed significant variance and are included in the BioModel were selected for subsequent sensitivity analysis in Step 2.

\subsubsection{Step 2: Parameter sensitivity analysis}

Following the parameter selection (Step 1), a detailed sensitivity analysis was performed on the selected parameters, in order to evaluate the magnitude of the parameters' individual effect on specific simulation output variables. The output variables chosen were biogas and methane production, VFA and total ammonium nitrogen-TAN concentration, $\mathrm{pH}$, commonly reported as good indicators of the AD process performance (Boe et al., 2010; Labatut and Gooch, 2012). Values of the 
136 parameters selected in Step 1 were allowed to vary between lower and upper

137 boundaries, defined based on the literature assessment of Step 1, and sampling of the

138 available parameter space was performed with the Latin Hypercube Sampling (LHS)

139 method (McKay, 1992; McKay et al., 1979). LHS was an integral part of the analysis,

140 in order to make sure that the parameter values were selected from the whole range

141 available, avoiding bias and maintaining statistical accuracy. Concerning the

142 distribution of parameter intervals by the LHS method, uniform parameter distribution

143 was assumed (Manache and Melching, 2007), and the number of parameter sample sets

144 generated by the method was ten times the number of parameters selected for analysis.

145 Following the sampling process, simulations were performed with every set of

146 parameter samples generated previously. The length of the simulated periods

147 corresponded to the periods where experimental data were available. Furthermore, to

148 reduce computational demand, four approximately equidistant time points of each case

149 simulation period were selected and only the output variable values of these time points

150 were used thereafter.

151 Sampling-based Partial Rank Correlation Coefficient (PRCC) method (Marino et

152 al., 2008; Pennington, 2015; Wu et al., 2013; Zi, 2011) was used to perform sensitivity

153 analysis. As the PRCC method does not account for time as an independent variable,

154 PRCC analyses for the previously selected, equidistant time points were conducted

155 separately, in order to produce statistically representative results for complete

156 simulation periods. Further to that, for PRCC results to be considered relevant, their

157 probability values (p-values) were required to be smaller than 0.05 (Jackson and

158 Radunskaya, 2015). For each case study, results of the PRCC analyses for individual

159 time points were combined, providing an aggregate PRCC value over the entire 
160 simulated period. Parameters were ranked according to their PRCC values to define the

161 most sensitive parameters with respect to each model output variable specified in Step

162 2. Both LHS and the PRCC analyses were carried out using the MATLAB-based

163 Sampling and Sensitivity Analyses Tool (SaSAT) (Hoare et al., 2008).

$164 \quad$ 2.3.3 Step 3: Parameter estimation

165 After identification of the most sensitive parameters in Step 2, numerical estimation

166 of their values was performed for both case studies. Variation in parameter values was

167 allowed according to lower and upper parameter boundaries specified in Step 2. The

168 parameters were estimated by minimization of the sum of squares of the differences

169 between predicted and experimental data sets (see Table SIII of the Supplementary

170 material). For the optimization task, the Simulated Annealing (SA) method was used

171 (Ingber, 1996; Kirkpatrick et al., 1983). Implementation of the method was done in

172 MATLAB, using the simulannealbnd function. Each case study was simulated with 250

173 iterations (a number used also by López and Borzacconi (2010)), in three consecutive

174 parameter estimation cycles to support the results of the stochastic optimization method

175 statistically. At the last step, SA iteration histories, objective function values and

176 estimated parameter values were collected from all simulations, and were used for

177 comparing the different scenarios on a quantitative and qualitative basis.

\subsubsection{Step 4: Validation and evaluation of the results}

179 First, performance criteria simulations - benchmark simulations - with the original

180 model parameter values were compared against simulations using the optimized

181 parameter values identified in Step 3, for both case studies used during parameter

182 estimation. Second, following the unification of optimized parameter values used in

183 case study 1 and 2 - by calculating the mathematical average of the respective 
184 parameter values - validation of optimized parameters was performed with the data of 185 three lab-scale CSTR experiments. Finally, conclusions were drawn based on the results 186 of validation.

\subsection{Case studies}

188 Below a short overview of the two experimental case studies, which were used during parameter estimation is provided. For further details on simulated substrate and process characteristics, see the Supplementary material, Table SIV and SV.

\subsubsection{Case study 1 (C1)}

Process data was collected from the doctoral dissertation of Schön (2009). In his work, the author investigated the applicability of ADM1 for the simulation of the AD process of a demonstration biogas plant, and lab-scale reactors fed only with manure.

The reactor selected for simulation had a volume of $75 \mathrm{~L}$ and was operated at mesophilic conditions $\left(37^{\circ} \mathrm{C}\right)$, with a hydraulic retention time (HRT) of 10 days, in four consecutive periods. Period 1 (day 0-8): no influent feed, operated as batch with only inoculum. Period 2 (day 9-15), Period 3 (day 16-22) and Period 4 (day 23-30) fed solely with manure of varying composition (Supplementary material, Table SIV). Due to the simplicity of the experimental setup and the availability of relevant data such as input manure characteristics, biogas production and $\mathrm{pH}$, this case was selected as the initial 202 case study for analysis.

\subsubsection{Case study 2 (C2)}

204 A continuous lab-scale experiment, carried out by Wang et al. (2016) using GTO 205 and ammonia as co-substrates, was used as the second case study. The reactor had a 206 working volume of $1.8 \mathrm{~L}$, its inoculum originated from digestion of a mixture of cattle 207 and pig manure, while cattle manure served as the primary substrate for reactor feeding 
208 (Supplementary material, Table SV). Reactor temperature was kept at $54{ }^{\circ} \mathrm{C}$ throughout

209 the whole experiment. Feeding took place with an HRT of 15 days, throughout the

210 experiment. The experiment was divided into two main phases; in the first phase,

211 manure feed was mixed with rapidly increasing concentrations of GTO, raising the

212 organic loading rate (OLR) from 3.2 g-VS L-1 $\mathrm{d}^{-1}$ to 5 g-VS L $\mathrm{L}^{-1} \mathrm{~d}^{-1}$ in 54 days, which

213 ended with the collapse of the reactor. Following re-inoculation, the reactor in the

214 second phase was fed with manure and a gradually increasing concentration of GTO,

215 reaching from 3.2 to 4 g-VS L ${ }^{-1} \mathrm{~d}^{-1}$ added organic material in 91 days, after which OLR

216 was kept stable. Meanwhile, ammonia addition in this last period increased from 2.1 to

2175 g-N L ${ }^{-1}$, during the course of 157 days. Thus for the simulation, 9 feeding periods

218 were defined, based on data provided by Wang et al. (not shown).

\section{Results and Discussion}

220 Base case simulations for the two case studies (C1 and C2) were generated with the 221 original BioModel parameters. The response of the model in terms of biogas or methane 222 productivities, and total VFA concentrations (where applicable) is shown in Figure 2a

223 (C1) and Figure 2b (C2), and are discussed in the following sections. pH simulations

224 were included in the Supplementary material (Figure S1 and S2).

Following the steps outlined in the systematic methodology, 44 parameters were initially selected in Step 1 for sensitivity analysis, with lower and upper boundaries defined based on the smallest and largest values reported for anaerobic digestion of complex substrates. The list of initially selected parameters, along with their lower and upper limits, can be found in the Supplementary material, Table SVI. In Step 2, the most sensitive parameters were identified for the individual estimation case studies 
232 initial parameters tested, model output variables were found to be sensitive to mainly 13

233 specific parameters. These 13 parameters included: $\mathrm{Hydr}_{\text {carb,in, }} \mathrm{Hydr}_{\text {prot,in, }}, \mathrm{Ks}_{\mathrm{AA}}, \mathrm{Ks}_{\mathrm{HPr}}$,

$234 \mathrm{Ks}_{\mathrm{HVal}}, \mathrm{Ks}_{\mathrm{HAc}}, \mathrm{Ki}_{\mathrm{NH} 3, \mathrm{HAc}}, \mathrm{pKh}_{\mathrm{Ac}}, \mathrm{Kd}_{\mathrm{AA}}, \mathrm{Kd}_{\mathrm{HPr}}, \mathrm{Kd}_{\mathrm{HBut}}, \mathrm{Kd}_{\mathrm{HVal}}$ and $\mathrm{Kd}_{\mathrm{HAc}}$. These

235 parameters and their quantified effect (PRCC values) on the output variables are shown

236 in Figure 3. As seen from the graphs, parameter effects show significant variations

237 depending on the output variables considered, but the trends in PRCC values, and thus

238 the overall parameter effects on the simulated systems appear similar. Once the most

239 sensitive parameters were identified, Step 3 was then executed, the results of which are

240 discussed in the next sections, for each case study respectively.

\subsection{Case study 1 (C1)}

In the first benchmark simulation, the response of the model with the original set of parameters is shown in red color in Figure 2a. As observed, model response fitted well

244 the trend exhibited by experimental data, particularly in Periods 1, 2 and 3 at which biogas production increased - due to an increase in the organic loading rate - and then stabilized at a new steady state level. In contrast with the trend exhibited by the experimental data during Period 4, where biogas production is shown to decrease throughout the whole period, the model predicted a slight decrease at the beginning and subsequently reached a new steady state level. This discrepancy is explained by the fact that during this operational period experimental values were not recorded properly as pointed out by the authors. Figure 2a shows in green color the response of the model when the set of optimized parameters (see Table II) was used. Although qualitative improvement is difficult to assess, improvements in the fitting were obtained. This was

254 further confirmed by the value of the objective function, which was reduced from 0.498

255 to 0.356 representing a $28.5 \%$ improvement in the model response (Table I). 
256 Meanwhile, the quality of the $\mathrm{pH}$ simulation was unchanged and remained highly

257 accurate (see Figure S1 in Supplementary material). Compared to the ADM1 simulation

258 that is shown in Figure 2a in blue color, both the benchmark and optimized simulations

259 fit experimental data with high accuracy, especially in Period 2, where a rapid increase

260 in biogas productivity is observed. This indicates that the BioModel appeared to

261 produce more accurate simulations for anaerobic manure digestion than the ADM1.

\section{$262 \quad 3.2$ Case study 2 (C2)}

263 In the second benchmark simulation, the response of the model with the original set of

264 parameters is shown in Figure $2 b$ in red color. First, two operational periods can be

265 observed with a considerable degree of uncertainty. Operational Period 2 between days

26650 and 80, where simulated methane productivity increased more rapidly compared to

267 the experimental trend, while the simulated total VFA concentrations only reached

268 about half of the experimental values. Periods 8 and 9 (between day 300 and 420), on

269 the other hand, showed an opposite trend, with a significant delay in the decrease of

270 methane productivity and an overestimation in total VFA concentration simulated. The

271 value of the objective function for the benchmark simulation was found to be 461.289

272 (see Table I). Figure 2b shows in green the response of the model when the set of

273 optimized parameters (see Table II) were used. As observed, by using the optimized

274 parameters a significant improvement (82.5\%) was obtained in the objective function

275 value (see Table I), which is well represented by the satisfactory fit of the total VFA

276 experimental data - particularly between days 300 and 420 (see Figure 2b, bottom in

277 green). 


\subsection{Parameter set validation}

279

As a result of the parameter optimization process carried out using the two aforementioned case studies, a general set of estimated parameters was compiled (see Table II), with parameter boundaries defined based on the lowest and highest optimized parameter values used by the SA algorithm. For validating the above, generally applicable set of parameters, three case studies are described below. They were selected from a wide range of experiments, and covered manure co-digestion with carbohydrates, manure co-digestion with complex substrates and wastewater codigestion with complex substrates.

\subsubsection{Validation case study 1 (V1)}

Experimental material for the first validation case scenario was taken from Søndergaard et al. (2015), who investigated the effect of meadow grass on biogas productivity, when added to manure and co-digested in CSTR-type reactors (Supplementary material, Table SVIII). By gradually increasing the concentration of meadow grass in the reactor, while using the same manure substrate, the experiment had four distinct feeding periods. Period 1 (day 0-12): manure feed without additional meadow grass. Period 2 (day 13-61): manure feed with $12 \mathrm{~g} \mathrm{~L}^{-1}$ meadow grass. Period 3 (day 62-91): manure feed with $23 \mathrm{~g} \mathrm{~L}^{-1}$ meadow grass. Period 4 (day 92-107): manure feed with $34 \mathrm{~g} \mathrm{~L}^{-1}$ meadow grass. Operation temperature was $54{ }^{\circ} \mathrm{C}$ and the working volume was $3.5 \mathrm{~L}$.

Benchmark simulations can be seen in Figure 4 in red, covering biogas productivity (top) and total VFA concentrations (bottom). Although the trend in total VFA concentrations is well captured by the BioModel, the total amounts are higher than the experimentally measured values. This is inversely true for the biogas productivity 
302 simulation, where the curve in the second half of Period 2 and in Period 3 and 4 falls

303 below the zone where experimental points are found. A clear improvement is achieved

304 in biogas productivity simulation using the general set of optimized parameters (curves

305 in green), as the curve becomes higher, fitting experimental data quite well in Period 2

306 and 3 and almost reaching experimental levels in Period 4. This is achieved by

307 increasing the simulated total VFA concentration slightly, which decreases simulation

308 accuracy somewhat further in Period 3 and 4. However, it also provides a better

309 description of the elevated total VFA concentration in the first half of Period 2 and

310 keeps the overall trend marked by experimental points.

$311 \quad 3.3 .2$ Validation case study 2 (V2)

312 A complex experiment published by Fitamo et al. (2016a, 2016b) served as source

313 material for the second validation case study, where the authors were co-digesting

314 mixed wastewater sludge (MS) with different urban organic wastes (UOW), such as

315 food waste, grass clippings and garden waste (Supplementary material, Table SIX).

316 Although the experiment involved two reactors, only the first one was considered in

317 present study. According to the description of the process, five feeding periods were

318 defined during the experiment, where the first covered only MS digestion and UOW

319 were added from Period 2. Between Period 2 and 5, the volatile solid-based mixture of

320 the four substrates was kept constant, meaning an approximately 10:68:15:7 mixing

321 ratio for mixed sludge, food waste, grass clippings and garden waste, respectively. The

322 distribution of feeding periods is as follows. Period 1 (day 0-75): MS digestion with an

323 HRT of 30 days. Period 2 (day 76-130): MS and UOW, HRT of 30 days. Period 3 (day

324 131-164): MS and UOW, HRT of 20 days. Period 4 (day 165-203): MS and UOW, 
325 HRT of 15 days. Period 5 (day 204-230): MS and UOW, HRT of 10 days. The reactor working volume was $3 \mathrm{~L}$ and operation temperature was $55^{\circ} \mathrm{C}$.

(Figure 5, curves in blue) indicate that biogas productivity (top) was captured very well,

329 along with total ammonia concentrations (bottom) outside Period 2. The total VFA simulation (middle), however, showed higher levels than seen during the experiment. By running simulations with the general set of optimized parameters (Figure 5, curves in green), significant improvements were achieved in fitting experimental data. Moreover, the simulation of total ammonia concentrations was now highly accurate, including that of Period 2, while the biogas productivity did not change considerably. Interestingly, simulated total VFA concentrations were lowered, to about half of what was simulated by Fitamo et al., providing a more accurate fit of experimental data. The simulated peak in Period 2 is most probably the result of starting the addition of UOW, where food waste contained high amounts of soluble lipids and carbohydrates. In contrast, low experimental values might indicate a microorganic community already well adapted to such concentrations.

\subsubsection{Validation case study 3 (V3)}

For the simulation of the third validation case study, lipid hydrolysis with first-order

343 kinetics was included as a structural part of the BioModel and it was set up assuming

344 inert and soluble fractions as described in Miron et al. (2000). Information about substrates and process decisions used during the case study were collected from Fezzani and Cheikh (2008, 2007), who described the co-digestion of olive mill wastewater and

347 olive mill solid waste at different HRTs and influent concentrations (Supplementary material, Table SX). The selected experiment used an influent total Chemical Oxygen 
349 Demand (TCOD) of 80 g-COD L ${ }^{-1}$ and was divided into three periods. Period 1 (day 0350 70): mixed feed with an HRT of 36 days. Period 2 (day 71-120): mixed feed with an 351 HRT of 24 days. Period 3 (day 121-150): mixed feed with an HRT of 12 days. The 352 reactor, despite being a tubular type, was completely mixed and had a working volume 353 of $18 \mathrm{~L}$. Operation temperature was $37^{\circ} \mathrm{C}$.

354 The response of the model with the original set of parameters is shown in Figure 6 355 in red. For operation Period 1 and 2, qualitatively the model prediction was good. However, the model was not able to forecast the third period at which a rapid decrease in biogas productivity and accumulation of VFA were observed. Another important aspect to point out is the sharp maximum in biogas productivity that the model predicts in Period 1 (between days 1-5), which happens early, yet is well in line with the experimental trend. Using the general set of optimized parameters and together with a slight increase in biogas productivity in Period 1 and 2 (Figure 6, top), a favorable increase in total VFA concentrations was experienced, visible principally in Period 3 (Figure 6, bottom). When compared to the performance of ADM1 as seen in Figure 6, the BioModel 365 performed better for the simulation of the initial increase in biogas production, however,

366 it was not able to simulate the rapid decline in biogas productivity (Figure 6, top) and

367 the proportional increase in total VFA concentrations (Figure 6, bottom) seen in the last 368 feeding period. This is most likely because the BioModel does not include a VFA

369 inhibition term effective on the growth of methanogenic microorganic groups, while 370 these inhibitory kinetics were added to the ADM1 by Fezzani and Cheikh. Another way 371 to decrease biogas productivity forecasted by the BioModel would have been the 372 reduction of the ammonia inhibition term $\mathrm{K}_{\mathrm{i}, \mathrm{NH}_{3}}$ (whose value was 0.259 before and 
373 became 0.275 after optimization), which takes effect on acetoclastic methanogens.

374 Being the overall most sensitive parameter among the 13 parameters identified in Step 2

375 of the methodology, this would have improved the fit in Period 3. Nevertheless, this

376 adjustment would not be feasible, as the authors have stated that ammonia concentration

377 was kept constant, at a low concentration of around $1.3 \mathrm{~g}-\mathrm{N} \mathrm{L}^{-1}$, throughout the whole

378 experiment (Fezzani and Cheikh, 2008). Assuming, however, that the rapid decline in

379 biogas productivity was due to the inhibition of acetoclastic methanogenic groups by

380 the accumulation of phenolic compounds (Borja et al., 1997) justifies the performance

381 of the BioModel, as this factor is not accounted for in the model and thus could not

382 decrease the productivity in Period 3.

383

384

385

386

387

388

389

390

391

392

393

394

395

396

\subsection{Evaluation}

The evaluation of above three validation case studies showed that by restricting future parameter estimations to the 13 sensitive parameters shown, significant improvements can be expected in simulation results. Further to the above, results of the present study indicate that in order to improve BioModel simulations, especially for wastewater-based co-digestion, process inhibition dynamics should be redesigned, considering certain effects that are currently missing in the microorganic growth equations. This will form part of subsequent studies carried out by the authors.

As a general comment and regarding the data accuracy of the three case studies, findings of present study and earlier work of Zielesny (2016) indicate that the inclusion of experimental measurement errors in objective function calculations might be favorable. Using such information, weighing the importance of experimental data points would become possible, in order to discount for the effect of outliers and improve the optimization system to be solved. 


\section{Conclusions}

398 The aim of present work was to develop a parameter estimation methodology, for

399 the improvement of anaerobic digestion modelling. By identifying the sensitive

400 parameters of a complex bioconversion model (BioModel) and estimating their optimal

401 values, it was found that the model was able to simulate the most relevant process

402 variables with improved accuracy. Although the microbial growth expressions in the

403 BioModel need further improvement for accurately describing certain inhibition

404 phenomena, using the optimized parameter set was proven to expand its applicability

405 for simulating both manure- and wastewater-based co-digestion cases, at either

406 mesophilic or thermophilic conditions.

\section{$407 \quad$ Acknowledgements}

408 The authors would like to thank Lars Ellegaard for providing valuable feedback on 409 present work. The project was supported by Energinet.dk, through the project ForskEL41012197 titled “Improving synergy and robustness of manure co-digestion process”.

\section{$411 \quad$ Conflict of Interest}

412 The authors claim no conflict of interest concerning any part of the work presented 413 here. 
415 1. Andrews, J.F., 1969. Dynamic model of the anaerobic digestion process. J. Sanit. 416 Eng. Div. 95, 95-116.

417 2. Angelidaki, I., Ellegaard, L., Ahring, B.K., 1999. A comprehensive model of 418 anaerobic bioconversion of complex substrates to biogas. Biotechnol. Bioeng. 63, 363419372.

420 3. Angelidaki, I., Ellegaard, L., Ahring, B.K., 1997. Modelling Anaerobic Codigestion 421 of Manure with Olive Oil Mill Effluent. Water Sci. Technol. 36, 263-270.

422 4. Angelidaki, I., Ellegaard, L., Ahring, B.K., 1993. A mathematical model for 423 dynamic simulation of anaerobic digestion of complex substrates: Focusing on 424 ammonia inhibition. Biotechnol. Bioeng. 42, 159-166.

425 5. Batstone, D.J., Keller, J., Angelidaki, I., Kalyuzhny, S. V., Pavlostathis, S.G., Rozzi, 426 A., Sanders, W.T.M., Siegrist, H., Vavilin, V.A., 2002. Anaerobic digestion model no. 1 427 (ADM1). IWA Publishing, London.

428 6. Batstone, D.J., Keller, J., Angelidaki, I., Kalyuzhnyi, S. V., Pavlostathis, S.G., 429 Rozzi, A., Sanders, W.T., Siegrist, H., Vavilin, V. a., 2002. The IWA Anaerobic 430 Digestion Model No 1 (ADM1). Water Sci. Technol. 45, 65-73.

431 7. Biernacki, P., Steinigeweg, S., Borchert, A., Uhlenhut, F., 2013. Application of 432 Anaerobic Digestion Model No. 1 for describing anaerobic digestion of grass, maize, 433 green weed silage, and industrial glycerine. Bioresour. Technol. 127, 188-194.

434 8. Boe, K., Batstone, D.J., Steyer, J.-P., Angelidaki, I., 2010. State indicators for 435 monitoring the anaerobic digestion process. Water Res. 44, 5973-5980. 
436 9. Borja, R., Alba, J., Banks, C.J., 1997. Impact of the main phenolic compounds of 437 olive mill wastewater (OMW) on the kinetics of acetoclastic methanogenesis. Process 438 Biochem. 32, 121-133.

439 10. Bułkowska, K., Białobrzewski, I., Gusiatin, Z.M., Klimiuk, E., Pokój, T., 2015. 440 ADM1-based modeling of anaerobic codigestion of maize silage and cattle manure 441 calibration of parameters and model verification (part II). Arch. Environ. Prot. 41, 20 44227.

443 11. Costello, D.J., Greenfield, P.F., Lee, P.L., 1991. Dynamic modelling of a single444 stage high-rate anaerobic reactor-I. Model derivation. Water Res. 25, 847-858.

445 12. Donoso-Bravo, A., Mailier, J., Martin, C., Rodríguez, J., Aceves-Lara, C.A., 446 Wouwer, A. Vande, 2011. Model selection, identification and validation in anaerobic 447 digestion: A review. Water Res. 45, 5347-5364.

448 13. Fezzani, B., Cheikh, R.B., 2008. Modelling of the mesophilic anaerobic co449 digestion of olive mill wastewater with olive mill solid waste using anaerobic digestion 450 model No. 1 (ADM1). Bioresour. Technol. 99, 6565-6577.

451 14. Fezzani, B., Cheikh, R.B., 2007. Anaerobic co-digestion of olive mill wastewater 452 with olive mill solid waste in a tubular digester at mesophilic temperature. Bioresour. 453 Technol. 98, 769-774.

454 15. Fitamo, T., Boldrin, A., Boe, K., Angelidaki, I., Scheutz, C., 2016a. Co-digestion of 455 food and garden waste with mixed sludge from wastewater treatment in continuously 456 stirred tank reactors. Bioresour. Technol. 206, 245-254.

457 16. Fitamo, T., Boldrin, A., Dorini, G., Boe, K., Angelidaki, I., Scheutz, C., $2016 b$.

458 Optimising the anaerobic co-digestion of urban organic waste using dynamic 459 bioconversion mathematical modelling. Water Res. 106, 283-294. 
460 17. Graef, S.P., Andrews, J.F., 1974. Mathematical modeling and control of anaerobic 461 digestion. Water Res. 8, 261-289.

462 18. Hill, D.T., Barth, C.L., 1977. A dynamic model for simulation of animal waste 463 digestion. J. Water Pollut. Control Fed. 49, 2129-2143.

464 19. Hoare, A., Regan, D.G., Wilson, D.P., 2008. Sampling and sensitivity analyses tools 465 (SaSAT) for computational modelling. Theor. Biol. Med. Model. 5, 4.

466 20. Ingber, L., 1996. Adaptive simulated annealing (ASA): Lessons learned. Control 467 Cybern. 25, 33-54.

468 21. Jackson, T., Radunskaya, A., 2015. Applications of Dynamical Systems in Biology 469 and Medicine. Springer-Verlag, New York.

470 22. Kirkpatrick, S., Gelatt, C.. D., Vecchi, M.. P.., 1983. Optimization by Simulated 471 Annealing. Science (80-. ). 220, 671-680.

472 23. Kleinstreuer, C., Poweigha, T., 1982. Dynamic simulator for anaerobic digestion 473 processes. Biotechnol. Bioeng. 24, 1941-1951.

474 24. Labatut, R. a., Gooch, C. a., 2012. Monitoring of Anaerobic Digestion Process to 475 Optimize Performance and Prevent System Failure, in: Proceedings of Got Manure?

476 Enhancing Environmental and Economic Sustainability. pp. 209-225.

477 25. López, I., Borzacconi, L., 2010. Modelling of slaughterhouse solid waste anaerobic 478 digestion: Determination of parameters and continuous reactor simulation. Waste 479 Manag. 30, 1813-1821.

480 26. Lübken, M., Wichern, M., Schlattmann, M., Gronauer, A., Horn, H., 2007.

481 Modelling the energy balance of an anaerobic digester fed with cattle manure and 482 renewable energy crops. Water Res. 41, 4085-4096. 
484 Sample Size and Distributional Assumptions, in: Proceedings of the 32nd Congress of 485 the IAHR. pp. 1-10. Performing Global Uncertainty and Sensitivity Analysis in Systems Biology. J. Theor. Biol. 254, 178-196.

29. McKay, M.D., 1992. Latin hypercube sampling as a tool in uncertainty analysis of computer models, in: Proceedings of the 1992 Winter Simulation Conference. pp. 557564.

30. McKay, M.D., Beckman, R.J., Conover, W.J., 1979. A Comparison of Three

493 Methods for Selecting Values of Input Variables in the Analysis of Output from a

494 Computer Code. Technometrics 42, 55-61.

495

31. Miron, Y., Zeeman, G., Van Lier, J.B., Lettinga, G., 2000. The role of sludge

496 retention time in the hydrolysis and acidification of lipids, carbohydrates and proteins during digestion of primary sludge in CSTR systems. Water Res. 34, 1705-1713. 32. Nguyen, H.H., 2014. Modelling of food waste digestion using ADM1 integrated with Aspen Plus. University of Southampton.

500 33. Pennington, H.M., 2015. Applications of Latin Hypercube Sampling Scheme and Partial Rank Correlation Coefficient Analysis to Mathematical Models on Wound

502 Healing. Western Kentucky University.

503 34. Ramirez, I., Mottet, A., Carrère, H., Déléris, S., Vedrenne, F., Steyer, J.P., 2009.

504 Modified ADM1 disintegration/hydrolysis structures for modeling batch thermophilic anaerobic digestion of thermally pretreated waste activated sludge. Water Res. 43,

$506 \quad 3479-3492$. 
Model No. 1 to describe the syntrophic acetate oxidation of poultry litter in

510 thermophilic anaerobic digestion. Bioresour. Technol. 167, 495-502.

511 36. Rosén, C., Jeppsson, U., 2006. Aspects on ADM1 Implementation within the BSM2

512 Framework, Technical report. Lund.

513 37. Sales-Cruz, M., Gani, R., 2006. Model discrimination and parameter estimation

514 through sensitivity analysis. Comput. Aided Chem. Eng. 21, 625-631.

515 38. Schön, M., 2009. Numerical Modelling of Anaerobic Digestion Processes in

516 Agricultural Biogas Plants. University of Innsbruck.

517 39. Siegrist, H., Renggli, D., Gujer, W., 1993. Mathematical modelling of anaerobic

518 mesophilic sewage sludge treatment. Water Sci. Technol. 27, 25-36.

519 40. Søndergaard, M.M., Fotidis, I.A., Kovalovszki, A., Angelidaki, I., 2015. Anaerobic

520 Co-digestion of Agricultural Byproducts with Manure for Enhanced Biogas Production.

521 Energy and Fuels 29, 8088-8094.

522 41. Wang, H., Fotidis, I.A., Angelidaki, I., 2016. Ammonia-LCFA synergetic co-

523 inhibition effect in manure-based continuous biomethanation process. Bioresour.

524 Technol. 209, 282-289.

525 42. Wu, J., Dhingra, R., Gambhir, M., Remais, J. V, 2013. Sensitivity analysis of

526 infectious disease models: methods, advances and their application. J. R. Soc. Interface

$527 \quad 10,20121018$.

528 43. Zi, Z., 2011. Sensitivity analysis approaches applied to systems biology models. IET Syst. Biol. 5, 336-346. 
530 44. Zielesny, A., 2016. From curve fitting to machine learning : an illustrative guide to 531 scientific data analysis and computational intelligence, second. ed. Springer 532 International Publishing, Switzerland. 
534 Table I. A comparison of objective function values throughout the two estimation case studies

\begin{tabular}{crrr}
\hline \multirow{2}{*}{ Experimental } & \multicolumn{2}{c}{ Objective function value using } & \\
\cline { 2 - 3 } case & reference & estimated & Improvement \\
& parameters & parameters & \\
\hline C1 & 0.498 & 0.356 & $28.5 \%$ \\
C2 & 461.289 & 80.950 & $82.5 \%$ \\
\hline
\end{tabular}


Table II. Parameter sets defined for the two estimation case scenarios and the generally applicable case, considering the minimum and

537 maximum values taken by the SA method and the calculated average values ${ }^{\text {a }}$

\begin{tabular}{|c|c|c|c|c|c|c|c|c|c|c|c|}
\hline $\begin{array}{c}\text { Parameter } \\
\text { category }\end{array}$ & Parameter & $\begin{array}{l}\text { Initial } \\
\text { value }\end{array}$ & \multicolumn{3}{|c|}{ Values taken in C1 } & \multicolumn{3}{|c|}{ Values taken in C2 } & \multicolumn{3}{|c|}{ General case $\left(C^{*}\right)$} \\
\hline $\begin{array}{c}\text { yield } \\
\text { coefficients }\end{array}$ & Hydr $_{\text {prot,in }}$ & 0.200 & 0.202 & 0.295 & 0.256 & 0.152 & 0.309 & 0.228 & 0.152 & 0.309 & 0.242 \\
\hline & $\mathrm{Ks}_{\mathrm{AA}}$ & 3.500 & 1.988 & 2.968 & 2.481 & 0.711 & 3.373 & 2.175 & 0.711 & 3.373 & 2.328 \\
\hline enplants & Ks & 0.259 & 0.035 & 0.179 & 0.113 & 0.074 & 0.204 & 0.137 & 0.035 & 0.204 & 0.125 \\
\hline & $\mathrm{Ks}_{\mathrm{HVal}}$ & 0.176 & 0.015 & 0.111 & 0.068 & 0.110 & 0.193 & 0.143 & 0.015 & 0.193 & 0.106 \\
\hline Higher $\mathrm{pH}$ & $\mathrm{pKh}_{\mathrm{Ac}}$ & 8.5 & 8.345 & 9.643 & 8.893 & 8.450 & 9.248 & 8.759 & 8.345 & 9.643 & $\mathbf{8 . 8 2 6}$ \\
\hline
\end{tabular}


boundary

\begin{tabular}{|c|c|c|c|c|c|c|c|c|c|c|c|}
\hline & $\mathrm{Kd}_{\mathrm{AA}}$ & 0.050 & 0.089 & 0.117 & 0.103 & 0.025 & 0.154 & 0.095 & 0.025 & 0.154 & 0.099 \\
\hline \multirow{2}{*}{ Cell death rates } & $\mathrm{Kd}_{\mathrm{HPr}}$ & 0.050 & 0.109 & 0.134 & 0.119 & 0.114 & 0.174 & 0.144 & 0.109 & 0.174 & 0.132 \\
\hline & $\mathrm{Kd}_{\text {HBut }}$ & 0.050 & 0.040 & 0.069 & 0.053 & 0.019 & 0.111 & 0.076 & 0.019 & 0.111 & 0.065 \\
\hline \multirow{2}{*}[\mathrm{d}^{-1}]{} & $\mathrm{Kd}_{\mathrm{HVal}}$ & 0.050 & 0.027 & 0.115 & 0.067 & 0.057 & 0.170 & 0.100 & 0.027 & 0.170 & 0.084 \\
\hline & $\mathrm{Kd}_{\mathrm{HAc}}$ & 0.050 & 0.026 & 0.050 & 0.041 & 0.010 & 0.018 & 0.013 & 0.010 & 0.050 & 0.027 \\
\hline
\end{tabular}

538

$539{ }^{a}$ Where Hydr are the hydrolysis constants; carb,in and prot,in indicate inert carbohydrate and protein substrates; Ks sub are the half-

540 saturation constants of substrates; AA indicates soluble proteins; HPr, HBut, HVal and HAc are propionic, butyric, valeric and acetic acid,

541 respectively; $K i_{N H 3 . H A c}$ is the ammonia inhibition constant effective on methanogenic microorganisms; $p K h_{A c}$ is the upper pH limit where

542 the microorganic growth rates are approximately $50 \%$ of the uninhibited rate; $K d_{\text {sub }}$ are the death rates of substrate degrading microorganic

543 cells. Default and suggested parameter values are shown in bold. 
545 Figure 1. Flowsheet representation of the systematic methodology used for analysis.

546 Figure 2. C1 and C2: Comparison of experimental and simulated biogas productivity, where BM_ben indicates the BioModel benchmark simulation and BM_opt

Figure 4. V1: Comparison of experimental and simulated biogas productivity (top) and total VFA concentrations (bottom), where BM_ben indicates the BioModel benchmark simulation and BM_opt indicates the BioModel simulation with optimized parameters. Dashed vertical lines represent the boundaries between feeding periods.

Figure 5. V2: Comparison of experimental and simulated methane productivity (top), total VFA concentrations (middle) and total ammonia concentrations (bottom), where BM_Fit indicates the BioModel simulation with default parameters (carried out by Fitamo et al.) and BM_opt indicates the BioModel simulation with optimized parameters. Dashed vertical lines represent the boundaries between feeding periods. 
Figure 6. V3: Comparison of experimental and simulated biogas productivity (top) and total VFA concentrations (bottom), where BM_ben indicates the BioModel benchmark simulation, BM_opt indicates the BioModel simulation with optimized parameters and ADM1 indicates the ADM1 simulation carried out by Fezzani \& Cheikh. Dashed vertical lines represent the boundaries between 572 feeding periods.

573 


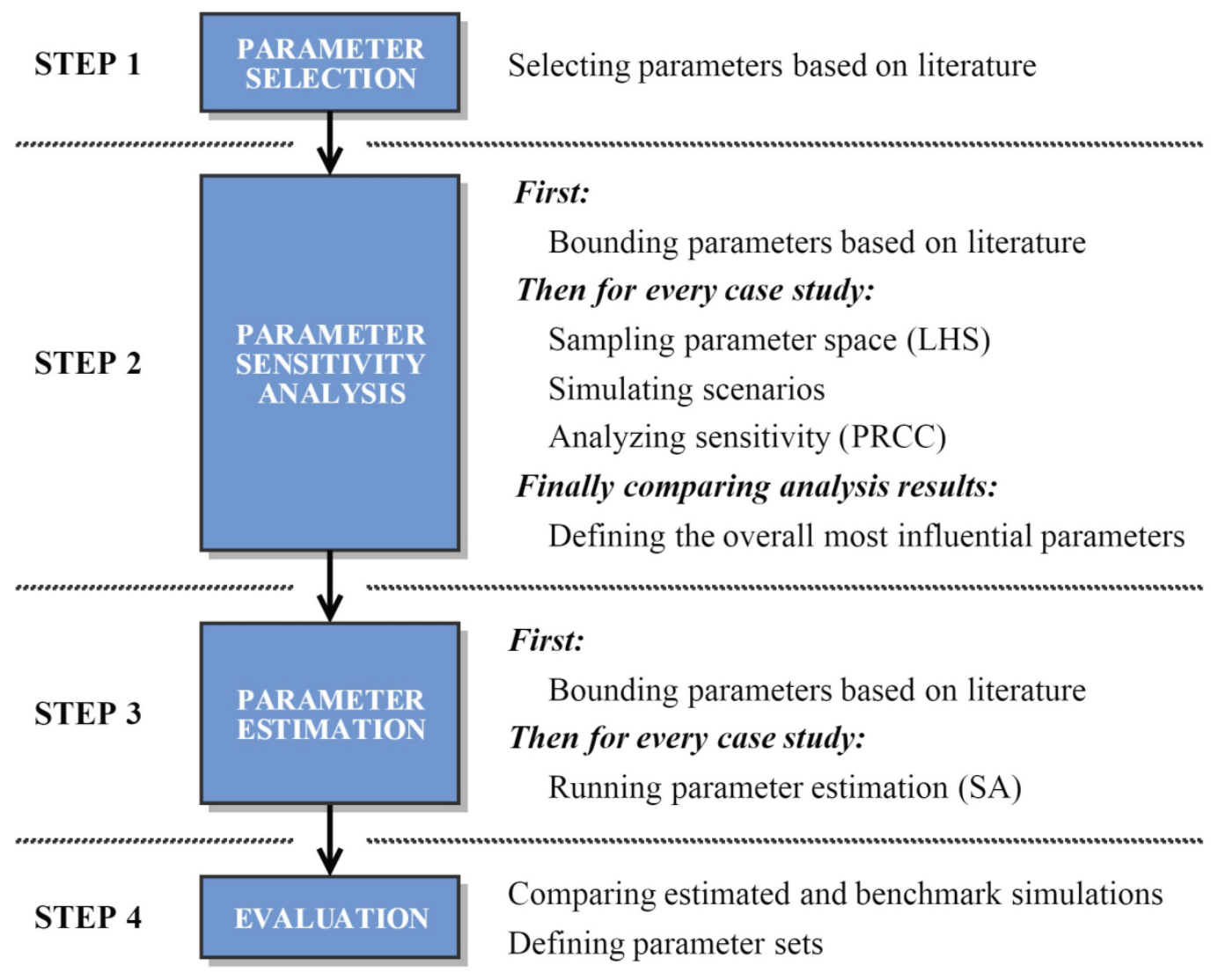


a

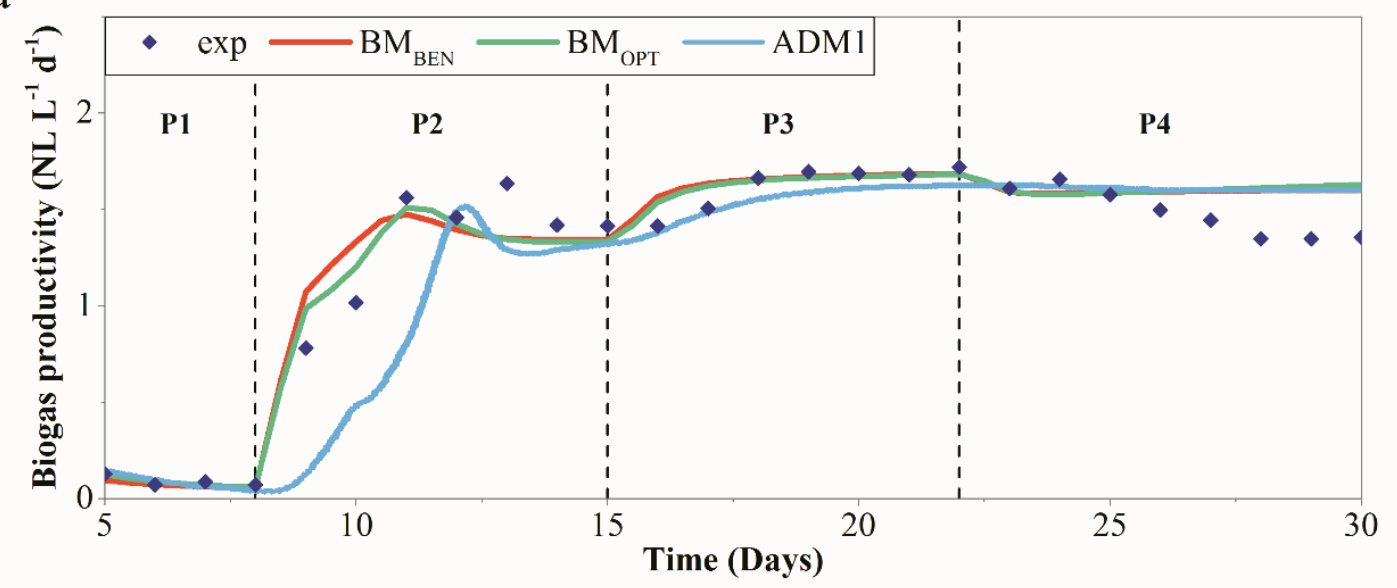

b

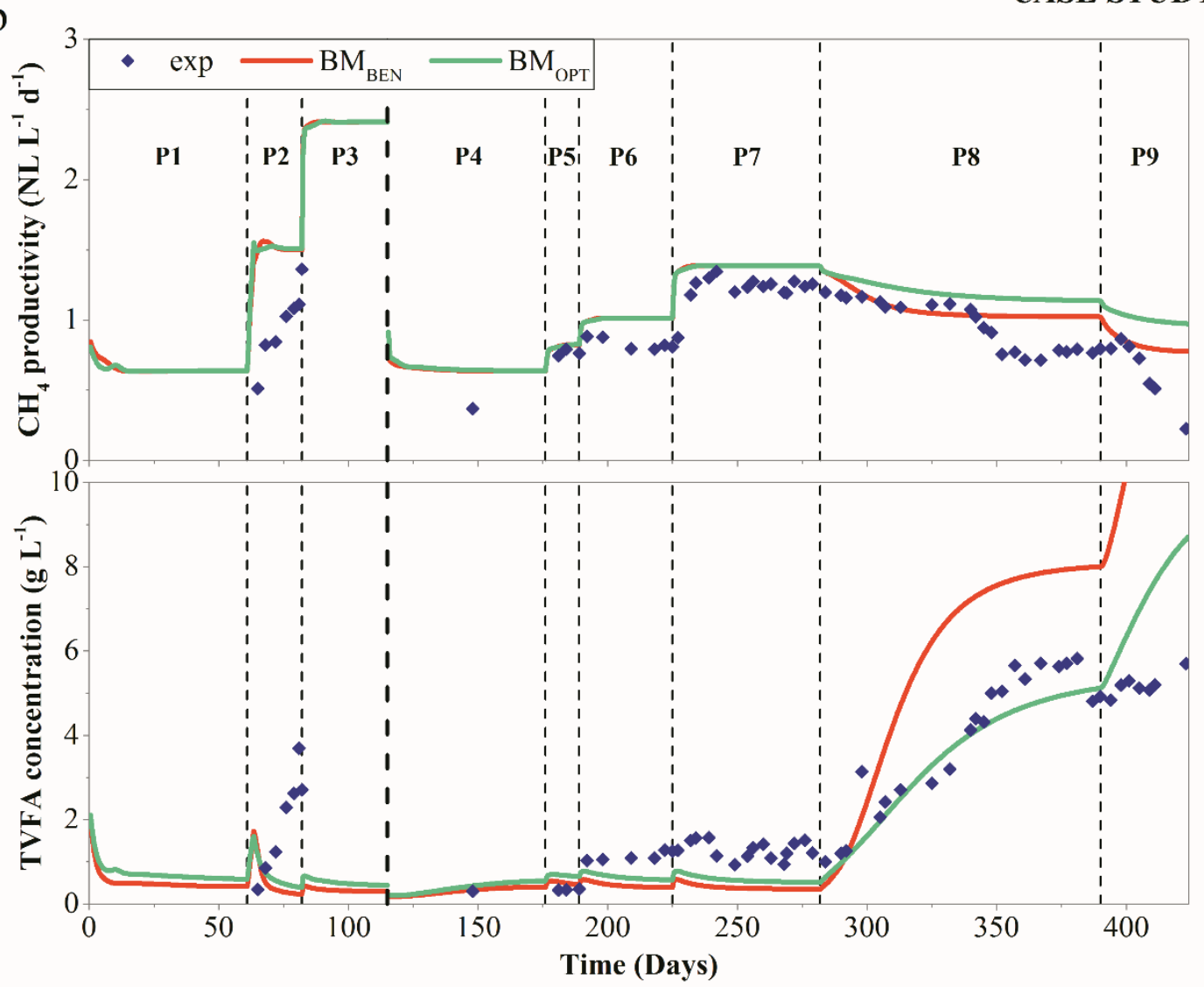

Figure 2 

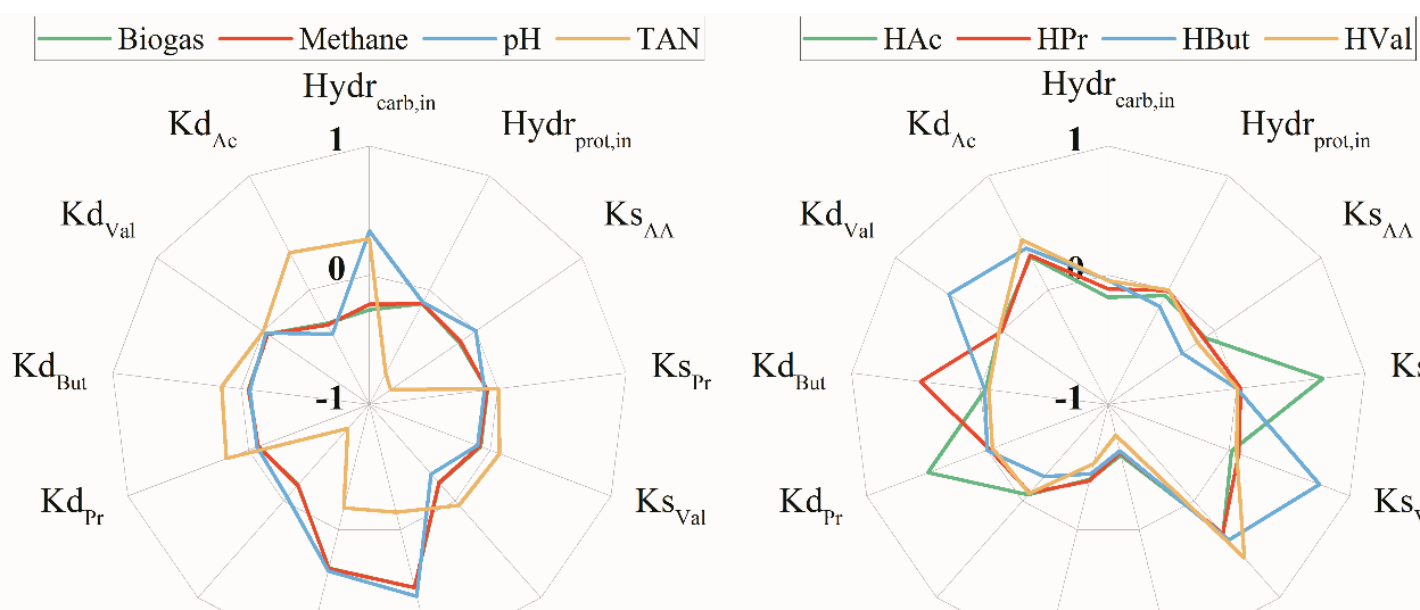

$\mathrm{Ks}_{\Lambda \Lambda}$

$\mathrm{Kd}_{\mathrm{val}}$

$\mathrm{Ks}_{\Lambda \Lambda}$

$\mathrm{Kd}_{\Lambda \Lambda}$

$\mathrm{Ks}_{\Lambda \mathrm{c}}$

$\mathrm{Ks}_{\mathrm{Pr}} \mathrm{Kd}_{\mathrm{But}}$

$\mathrm{Ks}_{\text {Val }} \quad \mathrm{Kd}_{\mathrm{Pr}}$

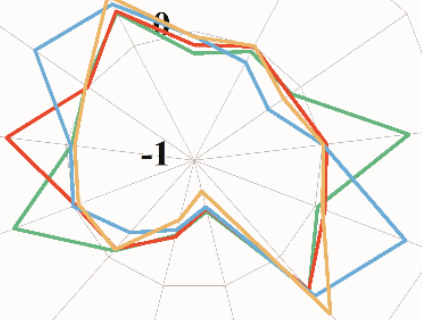

$\mathrm{Ks}_{\mathrm{Pr}}$

$\mathrm{Ks}_{\mathrm{Val}}$

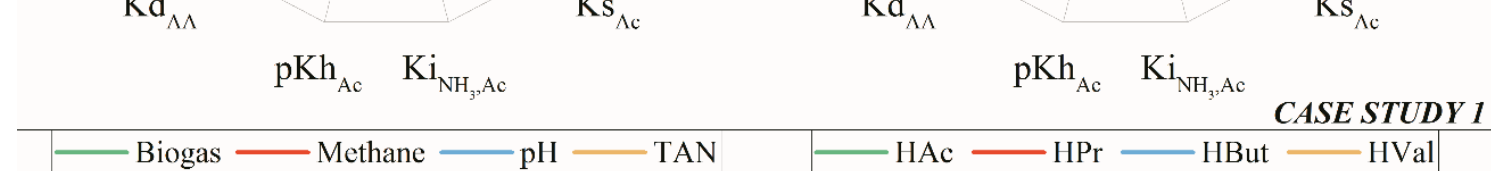

$\mathrm{Kd}_{\mathrm{Ac}} \quad \mathrm{Hydr}_{\text {carb,in }} \quad \mathrm{Hydr}_{\text {prot,in }}$

$\mathrm{Kd}_{\mathrm{Ac}} \quad \mathrm{Hydr}_{\text {carb,i }}$

Hydr $_{\text {prot,in }}$

$\mathrm{Kd}_{\text {Val }}$

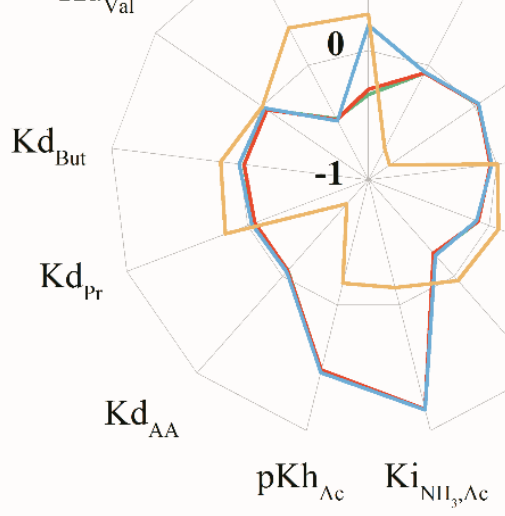

$\mathrm{Ks}_{\mathrm{AA}} \quad \mathrm{Kd}_{\mathrm{Val}}$

$\mathrm{Ks}_{\mathrm{AA}}$

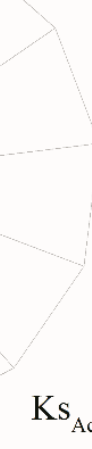

$\mathrm{Ks}_{\mathrm{Pr}} \quad \mathrm{Kd}_{\mathrm{Bu}}$

$\mathrm{Ks}_{\mathrm{Val}} \quad \mathrm{Kd}_{\mathrm{Pr}}$

$\mathrm{Kd}_{\mathrm{AA}}$

$\mathrm{Ks}_{\mathrm{Ac}}$

$\mathrm{pKh}_{\wedge \mathrm{c}} \quad \mathrm{Ki}_{\mathrm{NI}_{3}, \wedge \mathrm{c}}$

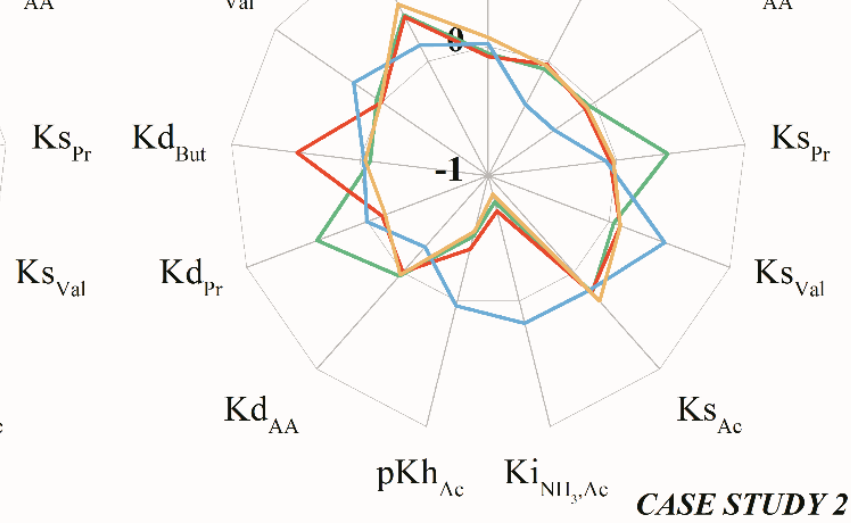

Figure 3 
582

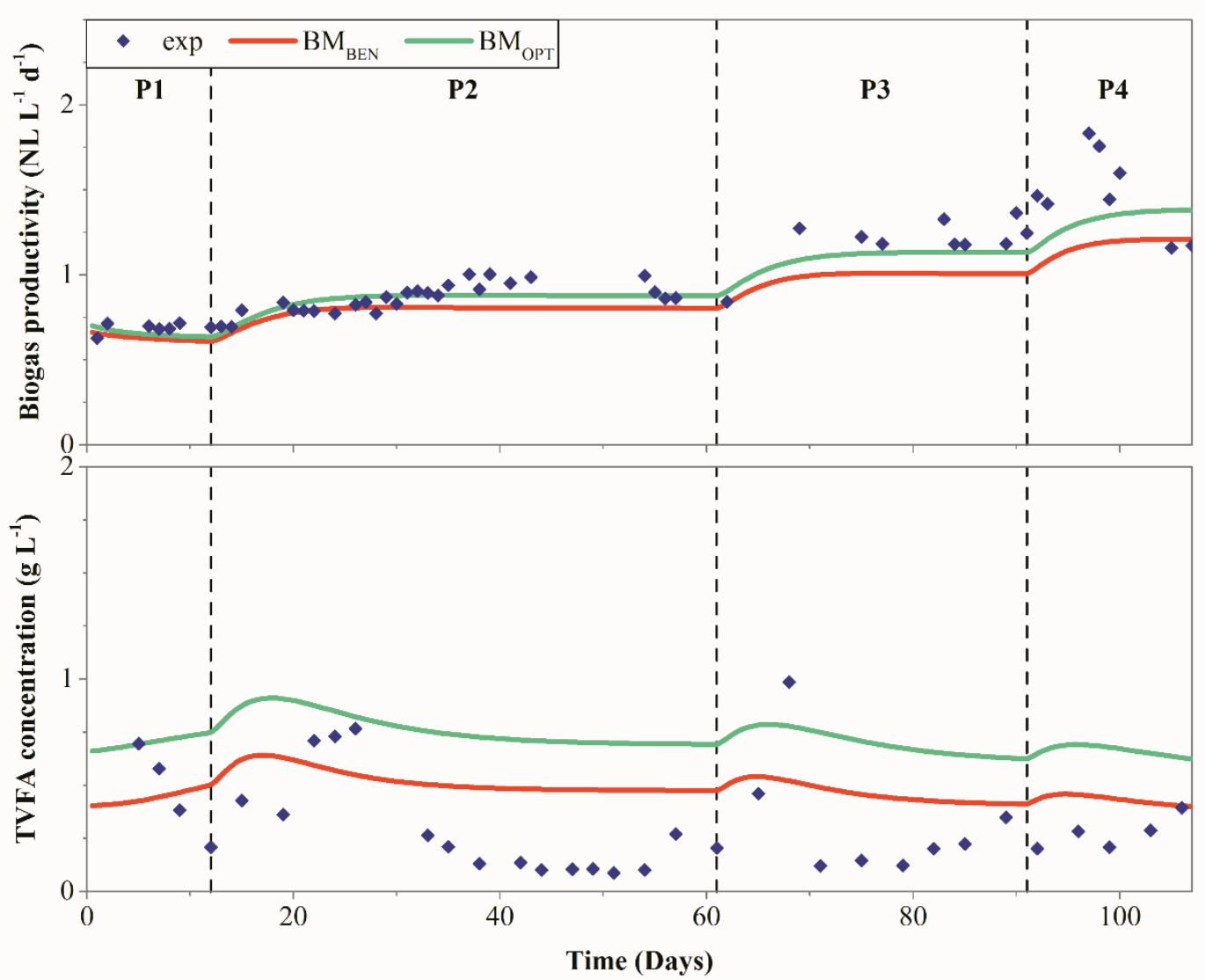

583

VALIDATION 1

584

Figure 4 
585
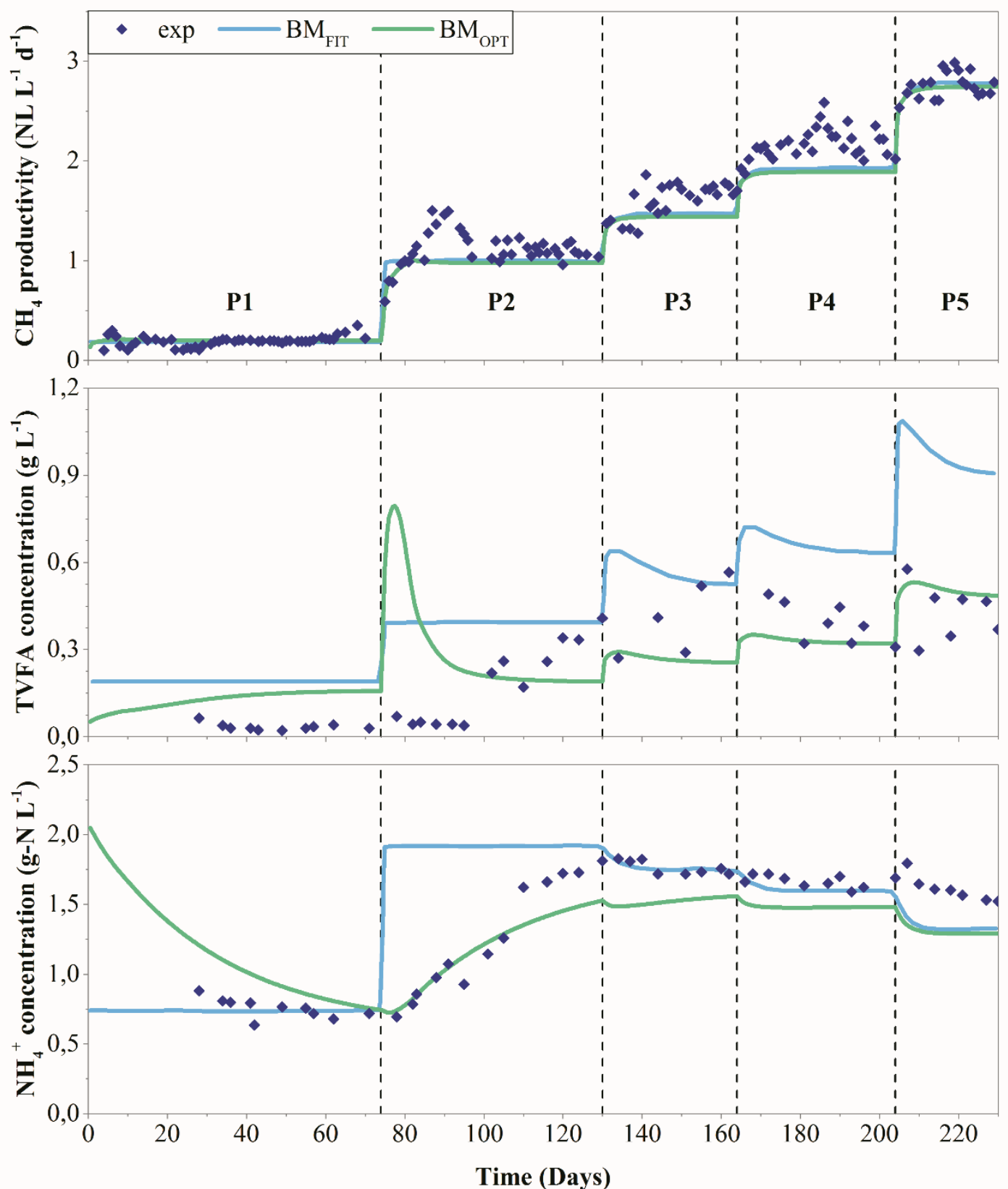

586

VALIDATION 2

Figure 5 


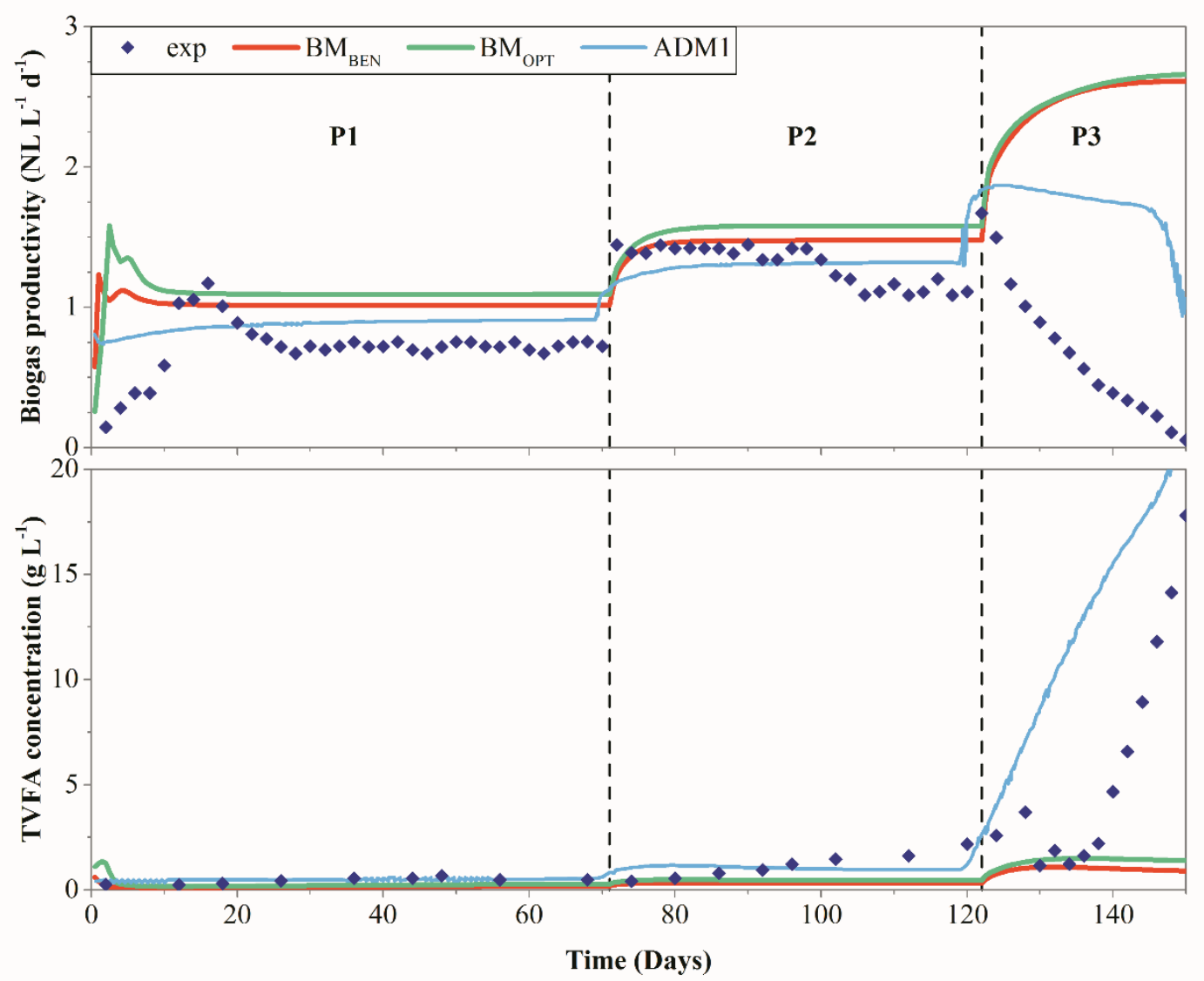

588

VALIDATION 3

Figure 6 